\title{
A divergence between underlying and final causes of death in selected conditions: An analysis of death registries in Peru
}

\author{
Rodrigo M Carrillo-Larco ${ }^{\text {Corresp., 1,2 , Antonio Bernabe-Ortiz }}{ }^{\text {Corresp. 3, 4, } 5}$ \\ 1 Department of Epidemiology and Biostatistics, Imperial College London, London, London, United Kingdom \\ 2 CRONICAS Center of Excellence in Chronic Diseases, Universidad Peruana Cayetano Heredia, Lima, Peru \\ 3 CRONICAS Center of Excellence in Chronic Diseases, Universidad Peruana Cayetano Heredia, Lima, Lima, Peru \\ 4 Faculty of Epidemiology and Population Health, London School of Hygiene \& Tropical Medicine, University of London, London, United Kingdom \\ 5 Facultad de Ciencias de la Salud, Universidad Peruana de Ciencias Aplicadas, Lima, Lima, Peru \\ Corresponding Authors: Rodrigo M Carrillo-Larco, Antonio Bernabe-Ortiz \\ Email address: r.carrillo-larco@imperial.ac.uk, antonio.bernabe@upch.pe
}

Background: The underlying cause of death is used to study country and global mortality trends and profiles. The final cause of death could also inform the ultimately cause of death in individuals with underlying conditions. Whether there is a pattern between the underlying and final cause of death has not been explored using national death registries. We studied what final causes of death were most common among selected underlying causes using national death registries in Peru, 2015.

Methods: Underlying and final causes of death were classified according to their ICD-10 codes. Underlying causes included chronic kidney disease (CKD), chronic obstructive pulmonary disease (COPD), hypertension, diabetes and selected cancers (cervix, breast, stomach, prostate, and lung). Final causes were categorized as: communicable, cardiovascular and cancers. Descriptive statistics were used.

Results: 77,065 death registries were analysed; cases had a mean age of 69.4 (SD: 19.3) years and were mostly men (53.9\%). When the underlying cause was hypertension, the most frequent final cause was cardiovascular diseases (82.3\%). For all the other underlying causes, the most frequent final cause was communicable diseases: COPD (86.4\%), CKD (79.3\%), cancer (76.5\%) and diabetes (68.3\%).

Conclusions: In four selected underlying causes of death there was a divergence with respect to the final cause, suggesting there was a shift from non-communicable to communicable causes. Although efforts should be deployed to prevent underlying non-communicable diseases, potential communicable complications should not be neglected. 
4

5

6

7

A divergence between underlying and final causes of death in selected conditions: An analysis of death registries in Peru

Short title: Underlying and final cause of death in Peru

Rodrigo M. Carrillo-Larco ${ }^{1,2}$, Antonio Bernabe-Ortiz ${ }^{2,3,4}$

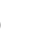

7 1. Department of Epidemiology and Biostatistics, School of Public Health, Imperial College London, London, United Kingdom

2. CRONICAS Center of Excellence in Chronic Diseases, Universidad Peruana Cayetano Heredia, Lima, Peru

1 3. Faculty of Epidemiology and Population Health, London School of Hygiene and 2 Tropical Medicine, London, United Kingdom

4. Facultad de Ciencias de la Salud, Universidad Peruana de Ciencias Aplicadas - UPC, Lima, Peru

15

\section{Corresponding Author:}

Antonio Bernabe Ortiz, MD MPH PhD

CRONICAS Centro de Excelencia en Enfermedades Crónicas, Universidad Peruana Cayetano Heredia

Address: Av. Armendáriz 497, Lima 18, Perú

Email: antonio.bernabe@upch.pe

Telephone: 511-2416978 


\section{ABSTRACT}

Background: The underlying cause of death is used to study country and global mortality trends and profiles. The final cause of death could also inform the ultimately cause of death in individuals with underlying conditions. Whether there is a pattern between the underlying and final cause of death has not been explored using national death registries. We studied what final causes of death were most common among selected underlying causes using national death registries in Peru, 2015.

Methods: Underlying and final causes of death were classified according to their ICD-10 codes. Underlying causes included chronic kidney disease (CKD), chronic obstructive pulmonary disease (COPD), hypertension, diabetes and selected cancers (cervix, breast, stomach, prostate, and lung). Final causes were categorized as: communicable, cardiovascular and cancers. Descriptive statistics were used.

Results: 77,065 death registries were analysed; cases had a mean age of 69.4 (SD: 19.3) years and were mostly men $(53.9 \%)$. When the underlying cause was hypertension, the most frequent final cause was cardiovascular diseases $(82.3 \%)$. For all the other underlying causes, the most frequent final cause was communicable diseases: COPD (86.4\%), CKD (79.3\%), cancer (76.5\%) and diabetes (68.3\%).

Conclusions: In four selected underlying causes of death there was a divergence with respect to the final cause, suggesting there was a shift from non-communicable to communicable causes. Although efforts should be deployed to prevent underlying noncommunicable diseases, potential communicable complications should not be neglected. 


\section{INTRODUCTION}

Global reports use the underlying cause of death to inform death trends and profiles.(Collaborators 2017a) This approach is relevant from a public health perspective because delaying or avoiding the underlying cause would prevent the chain of events leading to death. However, from a public health and clinical perspective, understanding the final cause of death is also relevant. For example, whether a patient with type 2 diabetes is likely to finally perish of a coronary event or sepsis, could guide what information should be provided to these patients (i.e., patient empowerment) and to health personnel looking after them. Information could thus target prevention of noncommunicable diseases, communicable disease, or both. From a clinical perspective, understanding the patterns between underlying and final cause of death could provide clinicians with evidence on what to prevent during hospitalizations or emergency visits. Finally, understanding the underlying-final cause of death profile could provide additional insights into the epidemiological transition. Although most countries now face a large (underlying) mortality burden of non-communicable diseases,(Collaborators 2017a; Collaborators 2017b; Collaborators 2017c) hence allocating resources to prevent them, understating what the final causes of death are could help to prevent complications, i.e., final causes of death. To the best of our knowledge, although multiple countries and international groups have made relevant efforts to improve and report underlying causes of death, little has been done to study the final causes of death and how these interact with the underlying ones. Consequently, we aimed to describe the final causes of death of selected underlying causes using national death registries in Peru, 2015. 
69

\section{METHODS}

\section{Data sources and subjects}

Death registries were requested from the Peruvian Ministry of Health.(Perú) These records compile death certificates from all health systems in Peru, though underreporting could be expected from facilities outside the ministry system (e.g., private clinics). Available data included underlying and final cause of death (ICD-10 codes), geographic location, sex and age.

For this study people aged 18 years or above were included, because most of the diseases of interest (e.g., type-2 diabetes mellitus) are uncommon in children. In addition, records in which the final cause was cardiac arrest (ICD-10: I48), chronic kidney disease (CKD) (ICD-10: N18), type 2 diabetes mellitus (ICD-10: E10, E11, E13), chronic obstructive pulmonary disease (COPD) (ICD-10: J41, J42, J44), hypertension (HTN) (ICD-10: I10), and selected cancers (ICD-10: C16 [stomach], C61 [prostate], C34 [bronchus and lung], C53 [cervix uteri], C50 [breast]), were excluded. Cardiac arrest cases in the final cause of death were excluded to improve the data quality, as it is not a clearly defined diagnosis. The other conditions, which were also the underlying causes of interest, were excluded to improve data quality and avoid overlapping between underlying and final cause of death, i.e., a registry with the same underlying and final cause which could imply data quality issues or an unintended error when filling in the certificate. The number of observations excluded at each step of data cleaning is depicted in Supplementary Figure 1. 


\section{Characteristics of data sources}

Although the analysed death registries have a national coverage, there could have been relevant under-reporting. In 2011 the coverage of the death registry was $53.8 \%$; in other words, roughly half of all the expected deaths were registered.(Salud) Moreover, there was wide variation across regions, ranging from $21.9 \%$ to $80.7 \%$ coverage.(Salud) Fortunately, though to the best of our knowledge it has not been quantified and reported, these coverage estimates have improved. At some extent, this argument has been supported by coverage reported by the Global Burden of Disease team.(Collaborators 2017a)

This underreporting would have implications on the results, interpretation and impact of this work. First, the findings should be understood in the context of the underreporting issue, meaning that these findings would not tell a complete picture but rather an introduction of what could be happening. Nonetheless, the results could tell a story that needs further verification, fostering the improvement of available registries as it has been done with the introduction of online registries in 2015.(Pardo et al.) Second, and with regards to this work and the communicable diseases outcome, these estimates could be under-reported assuming worse coverage in resource-limited settings, which would be where most communicable (infectious) diseases occur. If this is the case, we could expect higher rated of communicable diseases deaths.

\section{Variables}

We studied two causes of death as reported on death certificates based on ICD-10 codes. The underlying cause of death refers to that one which initiated the chain of pathological 
events that lead to death, while the final cause of death is the disease or event that produced death directly.(CDC)

We primarily focused on non-communicable underlying causes of death: CKD, diabetes, COPD, HTN and selected cancers (ICD-10 codes shown in the previous paragraph); we also generated one category for all others causes of death. We focused on these noncommunicable causes because they are leading causes of death.(Collaborators 2017a; Fitzmaurice et al. 2018; PAHO) On the other hand, the final causes of death were classified in three groups: communicable, cardiovascular (CVDs) and neoplasms. Their ICD-10 codes were classified according to the Global Burden of Disease Study criteria,(Collaborators 2017a) though with the following modifications: communicable final causes also included unspecified pneumonia (ICD-10: J18.9), unspecified bronchopneumonia (ICD-10: J18.0), and unspecified sepsis (ICD-10: A41.9); CVDs also description of ICD-10 codes included in the final causes, refer to Supplementary Table 1. have experienced a massive loss of information; in fact, the codes that were included in addition to the Global Burden of Disease classification accounted for the largest proportion of reported deaths. We chose this approach based on our knowledge of the local context. For example, sepsis coded as unspecified sepsis (ICD-10: A41.9) would have been considered a 'garbage code' by the Global Burden of Disease classification, but we included it in our communicable diseases category. We made this decision because we believe that these cases could have been undefined because of lack of 
laboratory resources to further characterize this condition. However, despite of this limitation, a sepsis would most likely be a communicable cause of death hence we included it in such group. For transparency sake, results according to the Global Burden of Disease classification are shown as Supplementary Figure 2.

\section{Statistical analysis}

Categorical variables are described as frequencies as well as proportions with $95 \%$ confidence intervals $(95 \% \mathrm{CI})$, and comparisons between them were computed with the Chi2 test. Numerical variables were described as mean and standard deviation. A sensitivity analysis was conducted with the final causes of death as per the Global Burden of Disease Study criteria, which follow a more strict classification. Analyses were conducted with STATA 13.0 (StataCorp, College Station, TX, US). Data was analysed without further re-distribution of ill-defined ICD-10 codes.

\section{Ethical considerations}

De-identified data was used; hence privacy of individuals was protected. Because this work was of low risk to human subjects and data were freely available, approval from an Institutional Review Board was not sought. 


\section{RESULTS}

\section{General characteristics}

152

153

154

155

156

157

158

There were 77,065 studied observations, with a mean age of 69.4 (SD: 19.3) years ranging from 18 to 115 ; there were more men $(53.9 \%)$. Of the selected underlying cause of death, diabetes accounted for 1.1\% (95\% CI: $1.0 \%-1.2 \%)$, CKD for $2.0(95 \% \mathrm{CI}$ : 1.9\%-2.1\%), COPD for $1.7 \%$ (95\% CI: $1.6 \%-1.8 \%)$, HTN for $2.4 \%$ (95\% CI: $2.3 \%$ $2.5 \%)$, and cancers for 6.4 (95\% CI: 6.2\%-6.6\%). There was a sex difference $(p<0.001)$, with more women deaths in the diabetes (1.2\% vs $1.0 \%)$, COPD (1.8\% vs $1.7 \%)$, HTN (2.5\% vs $2.2 \%)$ and cancer (7.3\% vs 5.7\%) groups (Supplementary Table 2$)$.

\section{Final causes of death}

Communicable diseases accounted for the largest share $(60.0 \%$; 95\% CI: 59.4\%-60.5\%), followed by cardiovascular (29.8\%; 95\% CI: 29.2\%-30.3\%) and cancers $(10.3 \%$; $95 \% \mathrm{CI}$ : 9.9\%-10.6\%). There was a sex difference $(p<0.001)$ with more women in the communicable (60.4\% vs 59.5\%) and cancer (11.2\% vs 9.4\%) categories (Supplementary Table 3).

Figure 1 shows that when HTN was the underlying cause of death, the largest final cause was CVDs (82.3\%). The other underlying causes of death had a non-trivial share of communicable diseases as final cause of death, with COPD showing the largest $(86.4 \%)$ share, followed by CKD (79.3\%), cancer $(76.5 \%)$ and diabetes $(69.3 \%$, Supplementary Table 4). Table 1 shows the top three final causes of death in each underlying cause. 


\section{Sensitivity analysis}

171 Supplementary Figure 2 shows that in sensitivity analysis the pattern of final cause of

172 death changed: all underlying causes had a large share of CVDs as final cause of death.

173 The profile of underlying and communicable final cause of death remained similar; where

174 COPD had the largest share (25.5\%) of final communicable diseases, followed by cancer

$175 \quad(18.5 \%)$, CKD $(14.3 \%)$ and diabetes (8.0\%, Supplementary Table 4). 


\section{Main findings}

The results showed a divergent profile between the underlying and final cause of death. In four non-communicable underlying causes of death, namely $\mathrm{CKD}$, COPD, diabetes and cancer, the final cause of death was largely a communicable condition; however, when HTN was the underlying cause, cardiovascular events were the predominant final cause. These results suggest that, even though Peru is undergoing epidemiological transition with non-communicable diseases leading the mortality rankings,(Collaborators 2017a; Huicho et al. 2009) communicable diseases still play a non-trivial role in the final cause of death. This calls for a synergism between health policies and practice of noncommunicable and communicable diseases. In addition, our findings could also hide a biological fact: reduced immunity in patients with underlying non-communicable diseases that could ultimately lead to communicable illnesses. Improving nutrition among these patients, advice and provide them with information to avoid communicable diseases may be relevant, and even to strengthen vaccination coverage (e.g., influenza) for these patients as it is the case with elderly.

Accounting for its limitations, this work adds to the literature evidence from the general population, i.e., not based on cohorts of specific diseases. This preliminary work based on death registries builds the first step to better characterize, hence understand, the complex interactions between non-communicable and communicable causes of death, i.e., multimorbidity (multi-mortality). The results do not suggest that Peru is at a different stage of 
diseases are more prevalent, communicable disease still account for a non-negligible proportion of final causes of death. We therefore recommend keeping strengthening care for non-communicable diseases, while keeping efforts up against communicable illnesses.

\section{Comparison with available evidence and interpretation of results}

A population-based cohort in Mexico showed that the rate ratio comparing diabetes versus no diabetes was larger when the outcome was infections (respiratory or gastrointestinal) that when it was cardiovascular mortality.(Alegre-Diaz et al. 2016) This observation agrees with our overall results, because the final cause of death when the underlying cause was diabetes was largely communicable illnesses. This similarity probably reflects poor awareness, treatment and control in diabetic patients.(Azañedo et al. 2017; Herrington et al. 2018; Huayanay-Espinoza et al. 2016; Lerner et al. 2013)

In Canada, a registry-based study found that in people with CKD the leading cause of death was cardiovascular events; in addition, they also reported that with worse kidney function, the risk of dying of an infectious cause increased.(Thompson et al. 2015) This observation had also been retrieved in the USA and Canada studying pneumonia fatalities.(James et al. 2009; Wang et al. 2011) To the best of our knowledge this evidence lack in Peru, where CKD mortality has only been studied in hospitals and patients in renal replacement therapy.(Herrera- Añazco et al. 2016) A hospital-based study in northern Peru reported that the first cause of death in CKD patients was cardiovascular diseases followed by infections.(Concepción-Zavaleta M et al. 2015) It seems that our primary results disagree with the available evidence. This could be explained by ascertainment of the outcome variable. Studies in high-income countries and those in restricted hospital-based populations could have followed a stronger 
222

223

224

225

226

227

228

229

230

231

232

233

234

235

236

237

238

239

240

241

242

243

244 methodology to assess the outcome. This hypothesis is supported by our sensitivity analysis in which cardiovascular events seemed to be the largest final cause of death when CKD was the underlying cause. This discrepancy and potential explanation call to cautiously interpret these findings and strengthen the mortality reporting systems in Peru.(Zolezzi 2017)

A Spanish COPD patient-based cohort reported different causes of death according to COPD profile; of note, in none the studied profiles a communicable disease prevailed over cardiovascular causes of death.(Golpe et al. 2018) This disagrees with our primary results, which could be explained by outcome ascertainment methods as previously discussed. However, this could also hide other clinical patters such a therapy. For example, COPD patients on inhaled corticosteroids may have worse outcomes, including death, in the presence of community-acquired pneumonia.(Liu et al. 2018) To the best of our knowledge there is no evidence on mortality or treatment patters in COPD patients in Peru. Although largely speculative, if inhaled corticosteroids were the leading treatment this could explain our results.

In the USA a registry-based study showed that breast and prostate cancer patients had a higher frequency of a non-cancer death.(Zaorsky et al. 2017) In addition, the top noncancer cause of death appeared to be cardiovascular conditions while the second one infectious illnesses;(Zaorsky et al. 2017) moreover, they also found that in people younger than forty-five years infections accounted for a relevant share of deaths, whereas in older people heart diseases surpassed infections.(Zaorsky et al. 2017) Our primary results showed that communicable conditions were the leading cause of death, whereas our sensitivity analysis agreed with Zaorsky et al.(Zaorsky et al. 2017) The discrepancy 
could be owed to different methods to assess the outcome or a different cardiovascular

profile between populations. With regards to the age finding, post-hoc analysis (data not shown in main results) yielded similar observations: for our primary outcome when the underlying cause of death was cancer and age was restricted to younger than fourth-five years, the $80.5 \%$ finally died of a communicable cause, whilst this percentage for people forty-five years and above was $76.2 \%$; on the other hand, when this post-hoc analysis was conducted with the outcome for sensitivity analysis, these percentages were $29.4 \%$ and $17.8 \%$, respectively. These results also suggests that when there is an underlying cancer, infectious causes of death may be more frequent in younger than older people. This finding deserves further dissection with larger sample size in both age groups to understand the profiles and risk factors of these sub-populations.

HTN is known to be a key risk factor for cardiovascular events, and our results confirm this knowledge. In addition, our results point that in some deaths with underlying HTN the final cause was a communicable disease. This could signal a complication of cardiovascular events, such as post-stroke infections.(Castaneda-Guarderas et al. ; Westendorp et al.)

\section{Public health and clinical relevance}

Our results show a divergence between the underlying and final cause of death, i.e., noncommunicable causes finally dying of a communicable illness. From a public health perspective these results could signal that CKD, COPD, diabetes and cancer patients should be aware of how to control their underlying condition, but also of the potential communicable complications so that they can early identify them. In addition, the results 
may call to provide health personnel and facilities with resources to successfully address both communicable and non-communicable diseases over these underlying conditions.

\section{Strengths and limitations}

The strengths of this work include using a large national death registry based on death certificates, and the analysis of both underlying and final causes of death. Nevertheless, the limitations included the lack of information on other health and socio-demographic variables such as adherence to treatment, disease control or educational attainment, which could modify and explain the patterns herein explored.(Herrington et al. 2018) However, our results still provide evidence of a divergence between the underlying and final cause of death. Future studies should explore the determinants at the individual and public health level of this divergence. Second, information was not available about the events between the underlying and final cause of death, should there have been any. For example, for deaths that occurred in a hospital, the final cause could have been a communicable disease even though the hospitalization was due to a non-communicable illness (e.g., COPD patient hospitalized due to a coronary syndrome though acquired a pneumonia which was the final cause of death). Nonetheless, our results raise awareness that some non-communicable diseases may have a non-negligible chance of dying of a communicable disease, signalling that these diagnoses should not be lost of sight even though other (non-communicable) conditions seemed more important at the time. This make it difficult to consider all potential possibilities. 


\section{Conclusions}

In a middle-income country undergoing epidemiological transition, there seems to be a divergence between the overall profile of the underlying and final cause of death. In four major non-communicable diseases - $\mathrm{CKD}, \mathrm{COPD}$, diabetes and cancers -, the final cause

of death was largely a communicable illness; whereas in hypertension it was a cardiovascular event. Although efforts should be deployed to prevent underlying noncommunicable diseases, potential communicable complications should not be neglected. 


\section{REFERENCES}

296

297

298

299

300

301

302

303

304

305

306

307

308

309

310

311

312

313

314

315

316

317

Alegre-Diaz J, Herrington W, Lopez-Cervantes M, Gnatiuc L, Ramirez R, Hill M, Baigent C, McCarthy MI, Lewington S, Collins R, Whitlock G, Tapia-Conyer R, Peto R, KuriMorales P, and Emberson JR. 2016. Diabetes and Cause-Specific Mortality in Mexico City. N Engl J Med 375:1961-1971. 10.1056/NEJMoa1605368

Azañedo D, Bendezú-Quispe G, Lazo-Porras M, Cárdenas-Montero D, Beltrán-Ale G, Thomas NJ, Ceballos RM, and Málaga G. 2017. Calidad de control metabólico en pacientes ambulatorios con diabetes tipo 2 atendidos en una clínica privada. Acta Médica Peruana 34:106-113.

Castaneda-Guarderas A, Beltran-Ale G Fau - Casma-Bustamante R, Casma-Bustamante R Fau Ruiz-Grosso P, Ruiz-Grosso P Fau - Malaga G, and Malaga G. [Registry of patients with stroke stated in a public hospital of Peru, 2000-2009].

CDC. Medical examiners' and coroners' handbook on death registration and fetal death reporting. [Accessed 20 September 2018]. URL: https://www.cdc.gov/nchs/data/misc/hb_me.pdf.

Collaborators GCoD. 2017a. Global, regional, and national age-sex specific mortality for 264 causes of death, 1980-2016: a systematic analysis for the Global Burden of Disease Study 2016. Lancet 390:1151-1210. 10.1016/s0140-6736(17)32152-9

Collaborators GDaH. 2017b. Global, regional, and national disability-adjusted life-years (DALYs) for 333 diseases and injuries and healthy life expectancy (HALE) for 195 countries and territories, 1990-2016: a systematic analysis for the Global Burden of Disease Study 2016. Lancet 390:1260-1344. 10.1016/s0140-6736(17)32130-x

Collaborators GDaIIaP. 2017c. Global, regional, and national incidence, prevalence, and years lived with disability for 328 diseases and injuries for 195 countries, 1990-2016: a 
systematic analysis for the Global Burden of Disease Study 2016. Lancet 390:1211-1259.

320

321

322

323

324

325

326

327

Concepción-Zavaleta M, Cortegana Aranda J, Ocampo Rugel N, and W. GP. 2015. Factores de riesgo asociados a mortalidad en pacientes con enfermedad renal crónica terminal. Rev Soc Peru Med Interna 28:72-78.

Fitzmaurice C, Akinyemiju TF, Al Lami FH, Alam T, Alizadeh-Navaei R, Allen C, Alsharif U, Alvis-Guzman N, Amini E, Anderson BO, Aremu O, Artaman A, Asgedom SW, Assadi R, Atey TM, Avila-Burgos L, Awasthi A, Ba Saleem HO, Barac A, Bennett JR, Bensenor IM, Bhakta N, Brenner H, Cahuana-Hurtado L, Castaneda-Orjuela CA, Catala-Lopez F, Choi JJ, Christopher DJ, Chung SC, Curado MP, Dandona L, Dandona R, das Neves J, Dey S, Dharmaratne SD, Doku DT, Driscoll TR, Dubey M, Ebrahimi H, Edessa D, ElKhatib Z, Endries AY, Fischer F, Force LM, Foreman KJ, Gebrehiwot SW, Gopalani SV, Grosso G, Gupta R, Gyawali B, Hamadeh RR, Hamidi S, Harvey J, Hassen HY, Hay RJ, Hay SI, Heibati B, Hiluf MK, Horita N, Hosgood HD, Ilesanmi OS, Innos K, Islami F, Jakovljevic MB, Johnson SC, Jonas JB, Kasaeian A, Kassa TD, Khader YS, Khan EA, Khan G, Khang YH, Khosravi MH, Khubchandani J, Kopec JA, Kumar GA, Kutz M, Lad DP, Lafranconi A, Lan Q, Legesse Y, Leigh J, Linn S, Lunevicius R, Majeed A, Malekzadeh R, Malta DC, Mantovani LG, McMahon BJ, Meier T, Melaku YA, Melku M, Memiah P, Mendoza W, Meretoja TJ, Mezgebe HB, Miller TR, Mohammed S, Mokdad AH, Moosazadeh M, Moraga P, Mousavi SM, Nangia V, Nguyen CT, Nong VM, Ogbo FA, Olagunju AT, Pa M, Park EK, Patel T, Pereira DM, Pishgar F, Postma MJ, Pourmalek F, Qorbani M, Rafay A, Rawaf S, Rawaf DL, Roshandel G, Safiri S, Salimzadeh H, Sanabria JR, Santric Milicevic MM, Sartorius B, Satpathy M, Sepanlou 
SG, Shackelford KA, Shaikh MA, Sharif-Alhoseini M, She J, Shin MJ, Shiue I, Shrime MG, Sinke AH, Sisay M, Sligar A, Sufiyan MB, Sykes BL, Tabares-Seisdedos R, Tessema GA, Topor-Madry R, Tran TT, Tran BX, Ukwaja KN, Vlassov VV, Vollset SE, Weiderpass E, Williams HC, Yimer NB, Yonemoto N, Younis MZ, Murray CJL, and Naghavi M. 2018. Global, Regional, and National Cancer Incidence, Mortality, Years of Life Lost, Years Lived With Disability, and Disability-Adjusted Life-Years for 29 Cancer Groups, 1990 to 2016: A Systematic Analysis for the Global Burden of Disease Study. JAMA Oncol. 10.1001/jamaoncol.2018.2706

Golpe R, Suarez-Valor M, Martin-Robles I, Sanjuan-Lopez P, Cano-Jimenez E, Castro-Anon O, and Perez de Llano LA. 2018. Mortality in COPD patients according to clinical phenotypes. Int J Chron Obstruct Pulmon Dis 13:1433-1439. 10.2147/copd.s159834

Herrera- Añazco P, Pacheco-Mendoza J, and Taype-Rondan A. 2016. La enfermedad renal crónica en el Perú: Una revisión narrativa de los artículos científicos publicados. Acta Médica Peruana 33:130-137.

Herrington WG, Alegre-Diaz J, Wade R, Gnatiuc L, Ramirez-Reyes R, Hill M, Solano-Sanchez M, Baigent C, Lewington S, Collins R, Tapia-Conyer R, Peto R, Kuri-Morales P, and Emberson JR. 2018. Effect of diabetes duration and glycaemic control on 14-year causespecific mortality in Mexican adults: a blood-based prospective cohort study. Lancet Diabetes Endocrinol 6:455-463. 10.1016/s2213-8587(18)30050-0

Huayanay-Espinoza IE, Guerra-Castanon F, Lazo-Porras M, Castaneda-Guarderas A, Thomas NJ, Garcia-Guarniz AL, Valdivia-Bustamante AA, and Malaga G. 2016. Metabolic control in patients with type 2 diabetes mellitus in a public hospital in Peru: a crosssectional study in a low-middle income country. PeerJ 4:e2577. 10.7717/peerj.2577 
364 Huicho L, Trelles M, Gonzales F, Mendoza W, and Miranda J. 2009. Mortality profiles in a

365

366

367

368

369

370

371

372

373

374

375

376

377

378

379

380

381

382

383

384

385

386

country facing epidemiological transition: an analysis of registered data. BMC Public Health 9:47. 10.1186/1471-2458-9-47

James MT, Quan H, Tonelli M, Manns BJ, Faris P, Laupland KB, and Hemmelgarn BR. 2009. CKD and risk of hospitalization and death with pneumonia. Am J Kidney Dis 54:24-32. 10.1053/j.ajkd.2009.04.005

Lerner AG, Bernabe-Ortiz A, Gilman RH, Smeeth L, and Miranda JJ. 2013. The "rule of halves" does not apply in Peru: awareness, treatment, and control of hypertension and diabetes in rural, urban, and rural-to-urban migrants. Crit Pathw Cardiol 12:53-58. 10.1097/HPC.0b013e318285ef60

Liu DS, Han XD, and Liu XD. 2018. Current Status of Community-Acquired Pneumonia in Patients with Chronic Obstructive Pulmonary Disease. Chin Med J (Engl) 131:10861091. 10.4103/0366-6999.230727

PAHO.

PAHO. Peru

Cancer

Profile

2013.

URL: https://www.paho.org/hq/dmdocuments/2014/PERU-CANCER-PROFILE-2013.pdf Accessed 21st July 2018.

Pardo K, Varigas J, Perez J, and Cortez-Escalante J. Sistema Nacional de Defunciones en Linea en el Peru: SINADEF. [Accessed September 19, 2018] URL: http://www.paho.org/relacsis/index.php/biblioteca-usuarios/reuniones-anuales$\underline{\text { relacsis/8va-reunion/posters-viii-reunion/54-viii-relacsis-poster-45/file }}$

Perú MdSd. Ministerio de Salud del Perú. Portal de Accesso a la Información Pública. URL: http://www.minsa.gob.pe/portada/transparencia/solicitud/frmformulario.asp $\quad$ Accessed 17th July 2018. 
387 Salud Md. Ministerio de Salud, Peru. Mortalidad General en el Peru 2007-2011. [Accessed 388 September 19, 2019]. URL: http://bvs.minsa.gob.pe/local/minsa/2722.pdf.

389 Thompson S, James M, Wiebe N, Hemmelgarn B, Manns B, Klarenbach S, and Tonelli M. 2015.

390 Cause of Death in Patients with Reduced Kidney Function. J Am Soc Nephrol 26:2504-

$391 \quad$ 2511. 10.1681/asn.2014070714

392 Wang HE, Gamboa C, Warnock DG, and Muntner P. 2011. Chronic kidney disease and risk of 393 death from infection. Am J Nephrol 34:330-336. 10.1159/000330673

394 Westendorp WF, Nederkoorn Pj Fau - Vermeij J-D, Vermeij Jd Fau - Dijkgraaf MG, Dijkgraaf 395 Mg Fau - van de Beek D, and van de Beek D. Post-stroke infection: a systematic review 396 and meta-analysis.

397 Zaorsky NG, Churilla TM, Egleston BL, Fisher SG, Ridge JA, Horwitz EM, and Meyer JE. 398 2017. Causes of death among cancer patients. Annals of Oncology 28:400-407. 10.1093/annonc/mdw604

Zolezzi A. 2017. Estadísticas de salud en el Perú: mejor llenado de información y su apropiada 401 utilización para promover la salud. Acta Médica Peruana 34:257-258. 
402

403

404

405

406

407

408

409

410

411

412

413

414

415

416

417

\section{FIGURES}

Figure 1: Final cause of death in selected underlying causes in Peru, 2015

This figure is to be read horizontally: starting from all deaths (first node or column), how many of these were due to the selected underlying causes of death (second set of nodes or second column), and of these how many were attributed to the studied final causes of death (last set of nodes or last column). The width of the links between nodes is relative to the proportion of deaths, i.e., the wider the link the larger the proportion. Interpretation: from all deaths that occurred in 2015, the largest proportion was due to other causes (wider link going from all deaths to other causes); also, when hypertension was the underlying cause of death, the largest final cause fall in the cardiovascular category (wider link going from HTN to CVDs). CKD = chronic kidney disease; COPD = chronic obstructive pulmonary disease; HTN = hypertension; CVD = cardiovascular diseases. Refer to Supplementary Table 5 for the exact estimates. 


\section{Table $\mathbf{1}$ (on next page)}

Top three final causes of death according to each underlying cause 
Table 1: Top three final causes of death according to each underlying cause

\begin{tabular}{|c|c|c|}
\hline \multicolumn{3}{|c|}{ Diabetes $(\mathrm{N}=363)$} \\
\hline Communicable $(\mathrm{N}=\mathbf{2 4 8})$ & Cardiovascular $(\mathrm{N}=112)$ & Cancer $(\mathbf{N}=3)$ \\
\hline Unspecified sepsis $(28.3 \%)$ & $\begin{array}{l}\text { Unspecified acute myocardial } \\
\text { infarction }(54.5 \%)\end{array}$ & $\begin{array}{l}\text { Malignant neoplasm of } \\
\text { gallbladder }(33.3 \%)\end{array}$ \\
\hline $\begin{array}{l}\text { Unspecified pneumonia } \\
\qquad(11.3 \%)\end{array}$ & Heart failure $(7.1 \%)$ & $\begin{array}{c}\text { Malignant neoplasm of } \\
\text { kidney, except renal pelvis } \\
(33.3 \%)\end{array}$ \\
\hline $\begin{array}{c}\text { Unspecified } \\
\text { bronchopneumonia }(3.2 \%)\end{array}$ & $\begin{array}{c}\text { Unspecified heart failure } \\
(7.1 \%)\end{array}$ & $\begin{array}{c}\text { Unspecified major salivary } \\
\text { gland }(33.3 \%)\end{array}$ \\
\hline \multicolumn{3}{|c|}{ Chronic Kidney Disease $(\mathrm{N}=511)$} \\
\hline Communicable $(\mathrm{N}=405)$ & Cardiovascular $(\mathrm{N}=103)$ & Cancer $(\mathrm{N}=3)$ \\
\hline Unspecified sepsis $(84.0 \%)$ & $\begin{array}{c}\text { Unspecified acute myocardial } \\
\text { infarction }(39.8 \%)\end{array}$ & Multiple myeloma $(33.3 \%)$ \\
\hline $\begin{array}{c}\text { Unspecified pneumonia } \\
(11.1 \%)\end{array}$ & Heart failure $(16.5 \%)$ & Oesophagus $(33.3 \%)$ \\
\hline $\begin{array}{c}\text { Unspecified } \\
\text { bronchopneumonia }(2.2 \%)\end{array}$ & $\begin{array}{c}\text { Unspecified heart failure } \\
(14.6 \%)\end{array}$ & $\begin{array}{c}\text { Unspecified myelodysplastic } \\
\text { syndrome }(33.3 \%)\end{array}$ \\
\hline \multicolumn{3}{|c|}{ Chronic Obstructive Pulmonary Disease $(\mathrm{N}=382)$} \\
\hline Communicable $(\mathrm{N}=330)$ & Cardiovascular $(\mathrm{N}=52)$ & Cancer $(\mathbf{N}=\mathbf{0})$ \\
\hline Unspecified sepsis $(54.6 \%)$ & $\begin{array}{l}\text { Unspecified acute myocardial } \\
\text { infarction }(48.1 \%)\end{array}$ & \\
\hline $\begin{array}{l}\text { Unspecified pneumonia } \\
(32.4 \%)\end{array}$ & $\begin{array}{l}\text { Unspecified heart failure } \\
\qquad(17.3 \%)\end{array}$ & \\
\hline $\begin{array}{c}\text { Unspecified } \\
\text { bronchopneumonia }(9.4 \%)\end{array}$ & Heart failure $(9.6 \%)$ & \\
\hline \multicolumn{3}{|c|}{ Hypertension $(\mathrm{N}=997)$} \\
\hline Communicable $(\mathrm{N}=175)$ & Cardiovascular $(\mathrm{N}=820)$ & Cancer $(\mathrm{N}=2)$ \\
\hline Unspecified sepsis $(72.6 \%)$ & $\begin{array}{c}\text { Unspecified acute myocardial } \\
\text { infarction }(51.8 \%)\end{array}$ & Unspecified colon $(50.0 \%)$ \\
\hline $\begin{array}{l}\text { Unspecified pneumonia } \\
\qquad(17.1 \%)\end{array}$ & $\begin{array}{c}\text { Stroke, not specified as } \\
\text { haemorrhage or infarction } \\
(19.8 \%)\end{array}$ & $\begin{array}{l}\text { Unspecified myelodysplastic } \\
\text { syndrome }(50.0 \%)\end{array}$ \\
\hline $\begin{array}{c}\text { Unspecified } \\
\text { bronchopneumonia }(6.3 \%)\end{array}$ & Heart failure $(5.4 \%)$ & \\
\hline \multicolumn{3}{|c|}{ Cancer $(\mathrm{N}=1189)$} \\
\hline Communicable $(\mathrm{N}=910)$ & Cardiovascular $(\mathrm{N}=147)$ & Cancer $(\mathrm{N}=132)$ \\
\hline Unspecified sepsis $(71.8 \%)$ & $\begin{array}{c}\text { Unspecified acute myocardial } \\
\text { infarction }(49.7 \%)\end{array}$ & $\begin{array}{c}\text { Carcinoma in situ, stomach } \\
(20.5 \%)\end{array}$ \\
\hline $\begin{array}{l}\text { Unspecified pneumonia } \\
(15.1 \%) \\
\end{array}$ & $\begin{array}{c}\text { Unspecified heart failure } \\
(20.4 \%)\end{array}$ & $\begin{array}{c}\text { Carcinoma in situ, prostate } \\
(14.4 \%)\end{array}$ \\
\hline Unspecified & Heart failure $(6.8 \%)$ & Carcinoma in situ, bronchus \\
\hline
\end{tabular}


\begin{tabular}{|l|l|l} 
bronchopneumonia (7.4\%) & and lung (6.8\%)
\end{tabular}

3 The Ns mean that, within each underlying cause of death, $\mathrm{N}$ people finally died of a

4 communicable, cardiovascular or cancer cause. For example, refer to diabetes as underlying

5 cause of death: among those whose underlying cause of death was diabetes, 248 finally died of a

6 communicable cause, 112 of a cardiovascular cause, and 3 of a cancer; within diabetes as the

7 underlying cause of death, and among those 248 who finally died of a communicable disease,

$828.3 \%$ (of 248) died of unspecified sepsis, $11.3 \%$ of unspecified pneumonia, and $3.2 \%$ of

9 unspecified bronchopneumonia (these were the top three final communicable causes of death

10 where diabetes was the underlying cause). The same interpretation follows for the other

11 underlying and final causes of death. 
Figure 1

Final cause of death in selected underlying causes, 2015

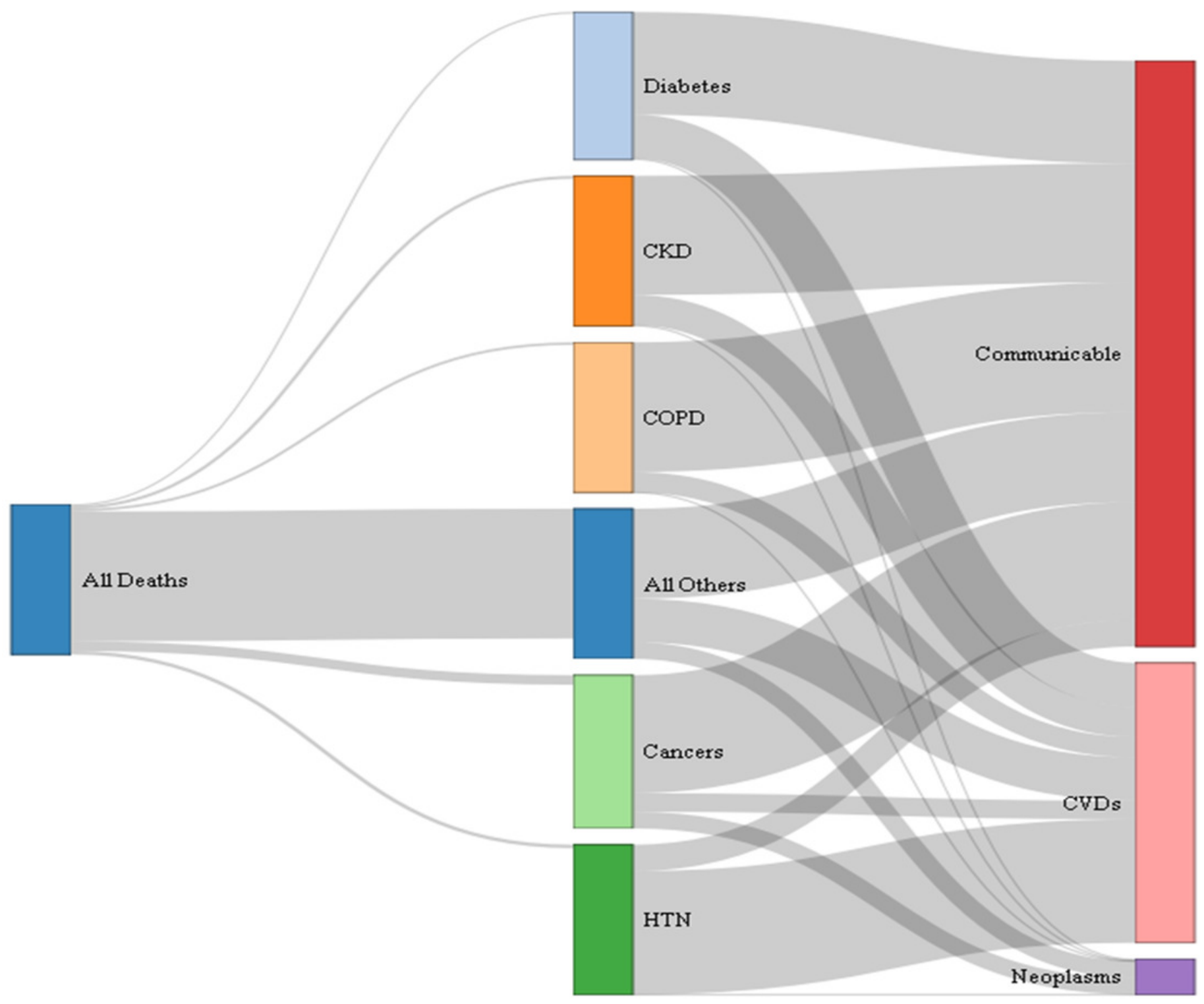

